\title{
The Effect of Percutaneous Screw Fixation of Lateral Malleolus on Ankle Fracture Healing and Function
}

\author{
Girgis Latif ${ }^{1}$, Hayder Al-Saadi ${ }^{1 *}$, Medhat Zekry², Malallah Ali Hassan ${ }^{1}$, Jamal Al Mulla ${ }^{1}$ \\ ${ }^{1}$ Rashid Hospital and Trauma Center, Dubai, UAE \\ ${ }^{2}$ Heart of England NHS Foundation Trust, Bimingham, UK \\ Email: *drhaydersaleh@gmail.com, "haalsaadi@dha.gov.ae
}

Received June 8, 2013; revised July 10, 2013; accepted July 19, 2013

Copyright (C) 2013 Girgis Latif et al. This is an open access article distributed under the Creative Commons Attribution License, which permits unrestricted use, distribution, and reproduction in any medium, provided the original work is properly cited.

\begin{abstract}
Purpose: To measure the effectiveness of using percutaneous intramedullary screw fixation of the lateral malleolus fracture on the healing and functional outcome of ankle fracture. Materials and Methods: Forty-six patients with Weber A and low Weber B displaced lateral malleolus fractures who underwent closed reduction and percutaneous internal fixation with an intramedullary, fully threaded, screw were retrospectively reviewed. A 3.5-mm, fully threaded, selftapping bone screw (stainless steel from Pelvic Set Synthes). The length of the screw varies between $100 \mathrm{~mm}$ and 120 $\mathrm{mm}$, depending on the fracture location and pattern. Results: All fractures united within an average time to union of 8.2 weeks. In all patients the average time to full weight bearing was 6.8 weeks, whereas that in patients with isolated lateral malleolus fractures was 4.5 weeks. There were no deep wound infections or complaints of painful hardware. At latest follow-up, functional results were excellent in, 25 patients (54.3\%) good in 20 (43.5\%), fair in (2.2\%). Conclusion: If reduction of the lateral malleolus fracture can be obtained in a closed fashion (with the aid of an image x-ray intensifier), we believe that fixation may be performed with an axial screw percutaneously. This technique is quick, safe and easy to do with less complication.
\end{abstract}

Keywords: Ankle Fracture; Lateral Malleolus; Intramedullary Screw

\section{Introduction}

Restoring the normal anatomy of the lateral malleolus has been recognized as the key to operative treatment of ankle fractures [1]. Yablon pointed out that the talus faithfully follows the lateral malleolus, and Harper showed that relatively minor lateral malleolus fractures allow for talar shaft and joint incongruity [1,2]. The treatment options for lateral malleolar fractures are either non operative or operative including; cerclage wiring, lag screws, a plate and screws, a hook plate, tension band wiring, axial pins, and axial screws [1-3]. Recently, Acumed nail introduced to fix the fibular fracture [4]. In 1963, the AO group introduced their well-known methods of fixation principles like buttress plate and screws and/or a lag screw, depending on the fracture pattern. These methods provide stable anatomic fixation and results of numerous clinical studies are excellent $[3,5,6]$.

It has been criticized by several authors because of the small amount of overlying soft tissues laterally and patients' complaints of pain over prominent hardware [7-9].

*Corresponding author.
Among the different methods of fixing lateral malleolus as an intramedullaryfixations using Steinmann pins [10] and Rush rods [11], however, apprehension about the hardware backing out has limited their usefulness.

Cancellous screws alone have also been used for fixation of Weber A fibula fractures [11,12], but, as with smooth pins, these fixation devices may allow rotation of the distal fragment. Several authors have described fixation of fibular fractures with an axial screw $[14,15]$.

At our institution which is Level-One Trauma Centre and Tertiary centre for Trauma in Dubai, UAE, we adopt internal fixation policy of simple Weber A and low Weber B fibular fractures with a long intramedullary screw. It has been utilized because it is felt that this technique is simpler than buttress plating and with less hardware complications. The long intramedullary screw also allows better purchase within the fibular canal than a smooth pin (while accommodating the distal fibular lateral bow), therefore eliminating hardware migration [5]. Furthermore, Bankston et al. demonstrated biomechanically that this particular fixation device was superior in strength, although not statistically followed up compared 
to other fixations with plate and screws [16]. They reported their clinical results using open reduction and internal fixation of lateral malleolus fractures with an intramedullary screw, which demonstrated stable fracture fixation (allowing early weight bearing) and a 100\% rate of union in their series.

Tamara D. Ray, at all, used intramedullary screw fixation for lateral malleolus fracture in 24 patients and they have good results [17].

\section{Patients}

Between 2006 and 2012 we retrospectively reviewed 280 patients who underwent open reduction and internal fixation for fractures about the ankle.

Fifty-nine of these patients underwent intramedullary fixation of a lateral malleolus fracture with an axially directed screw. Forty-six of these patients were followedup for an average of 63.4 weeks. Fracture types included in this study were 21 lateral malleolus fractures with tear of the deltoid ligament, 15 bimalleolar fractures, and 10 trimalleolar fractures. Hospital and clinic records were reviewed for evidence of early or late complications relating to the wound, hardware, reduction, and union. Any medial ankle surgery for open reduction and internal fixation of a medial malleolus fracture or repair of a deltoid ligament was also differentiated. Surgeon's operation notes records were also evaluated for length of immobilization, time to full weight bearing, and total length of follow-up. Patients' subjective findings at the time of last clinic visit were also documented. New patients were evaluated for anatomic healing and not for long term results related to degenerative arthritis. Of the 46 patients available for follow-up, 16 were female and 30 were male. Their average age was 39.5 years (range 18 - 67). Twenty one fractures were isolated lateral malleolus fractures, of which six had an open deltoid ligament repair in addition to open reduction and internal fixation of the lateral malleolus. Twenty-five patients had a medial malleolus fracture, with 15 of these being bimalleolar and 10 being trimalleolar. Thirty-six fractures were classified as Weber B and 10 as Weber A. Allmedial malleolus fractures were fixed with one or two cancellous screws. No poste rior malleolar fractures required fixation in this group. (Figures 1-3 showing examples of lateral malleolus fracture fixed by intramedullary screw done in Rashid Hospital and Trauma Center).

\section{Surgical Technique}

To be amenable to fixation with an intramedullary screw, a lateral malleolus fracture must be simple or minimally comminuted because intramedullary fixation will not reliably maintain length in comminuted fractures. Ideally, the lateral malleolus fracture should be of a transverse or short oblique configuration. The technique involves us

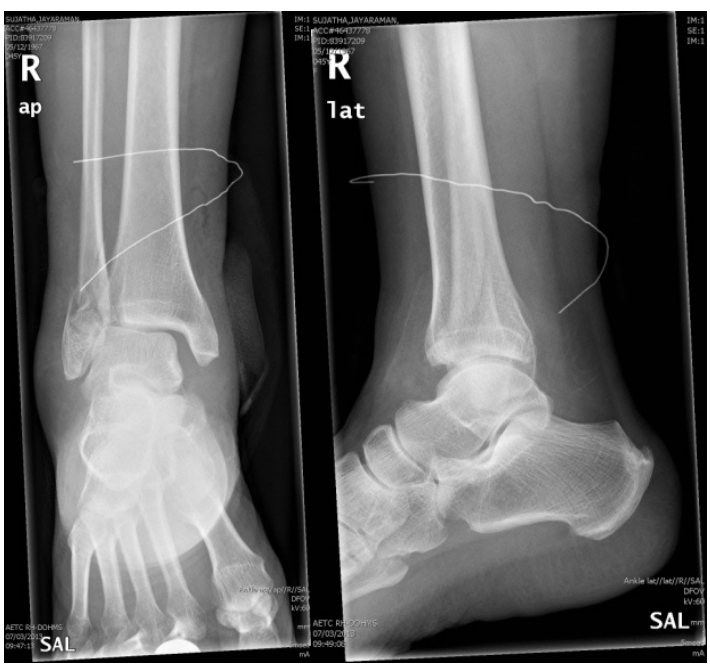

(a)

(b)

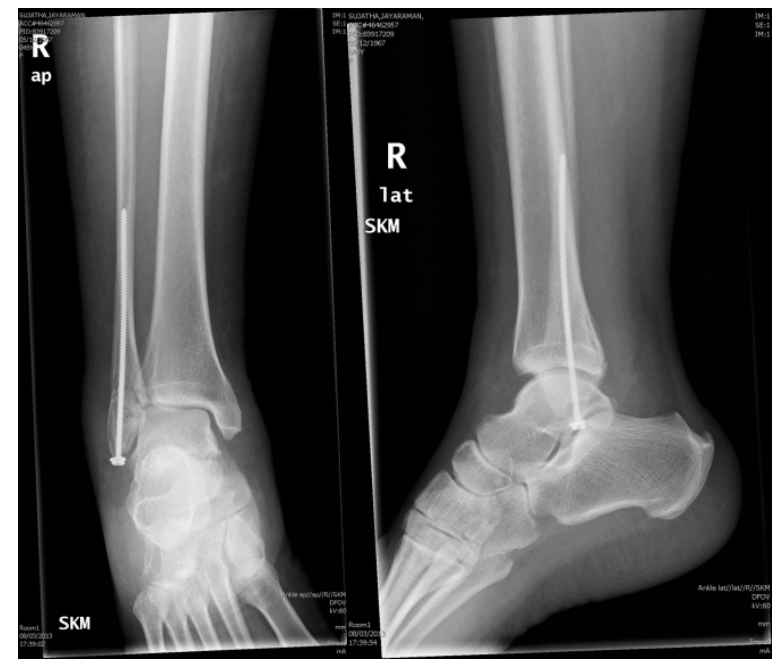

(c)

(d)

Figure 1. (a) and (b): Pre-operative X-Rays; (c) and (d): Post-operative X-Rays.

ing image intensification to aid anatomic reduction by inverting the foot and then achieving and maintaining fracture reduction with a towel clipper cutaneously (This technique may be more difficult in a markedly obese or swollen ankle). While the fracture is stabilized, a stab incision is made just distal to the tip of the lateral malleolus, and a hole is made in the tip of the lateral malleolus with a 2.5-mm drill bit trying to be somewhat posterior on the lateral malleolus tip (avoid anterior insertion). A 3.5-mm, fully threaded, self-tapping bone screw (stainless steel from Pelvic Set Synthes) is then passed across the fracture site and into the proximal fibular fragment .The screw is tightened until its head reaches the bone. It is not possible to make more compression at the fracture site by further tightening of the screw be cause it is a fully threaded screw and serrations are on both sides of fracture site. Electric power drill can be 


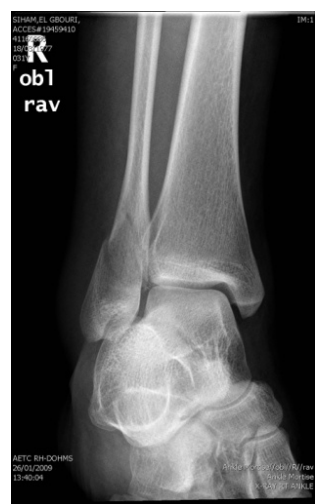

(a)

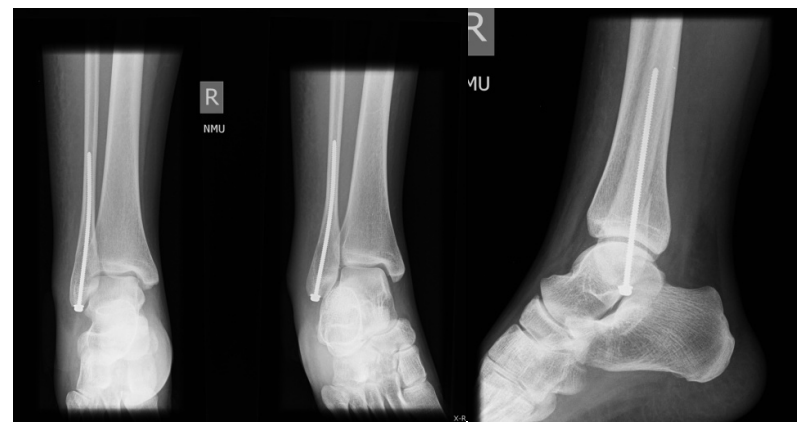

(c)

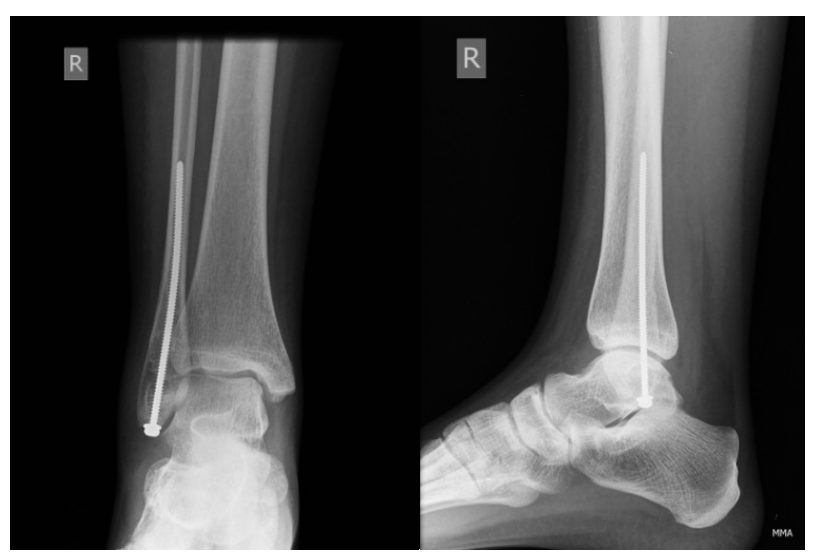

(e)

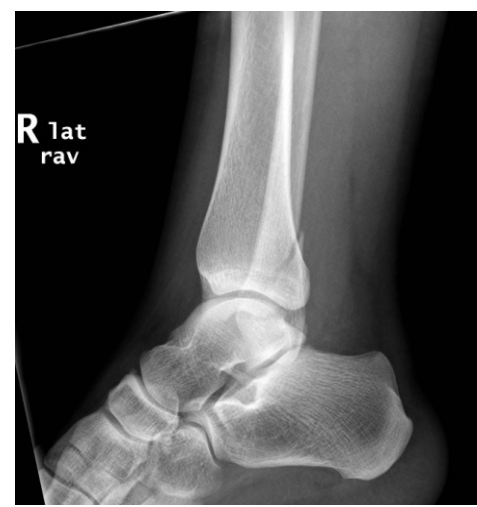

(b)

(d)

(f)
Figure 2. (a) and (b): Pre-operative X-rays; (c) and (d): Post-operative X-rays; (e) and (f): Follow up X-ray after four months showing good healing.

used to insert the screw to give the screw the enough power to be bent with the long axis of distal fibula. The length of the screw varies between $100 \mathrm{~mm}$ and $120 \mathrm{~mm}$, depending on the fracture location and pattern. When a medial malleolus fracture is present, a separate incision is made for open reduction of this fracture before lateral malleolar fixation and the lateral malleolus is then fixed. Intraoperative roentgenograms (AP, lateral, mortise, and stress views) are always obtained to confirm the reduction of the fracture, the position of the screw, and the stability of the syndesmosis. The wound is then closed

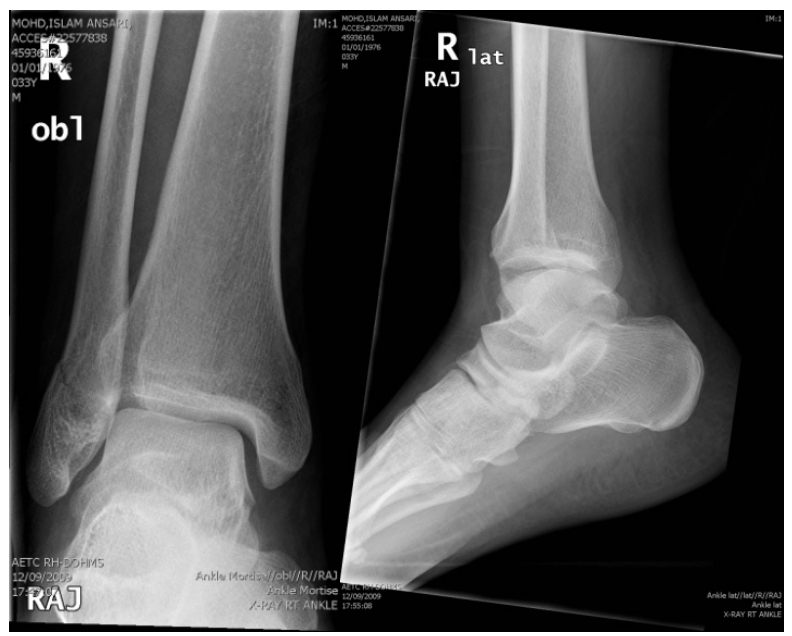

(a)

(b)

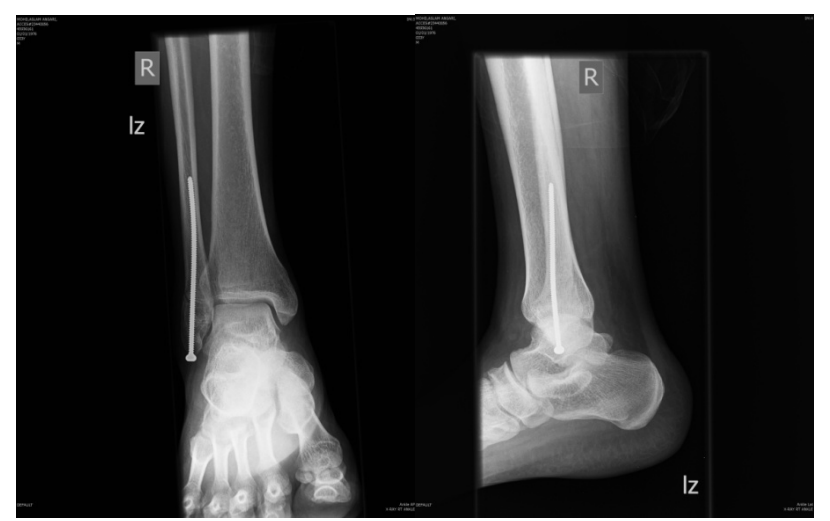

(c)

(d)

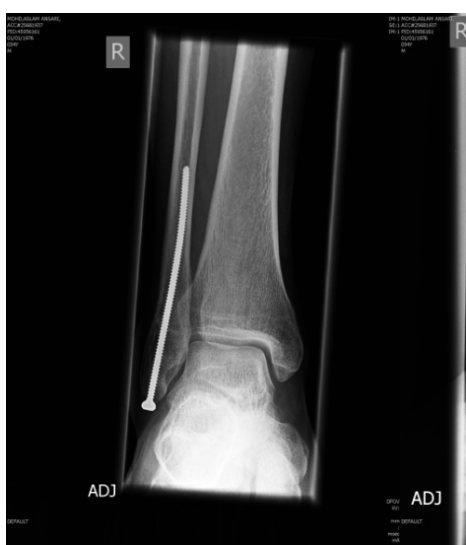

(e)

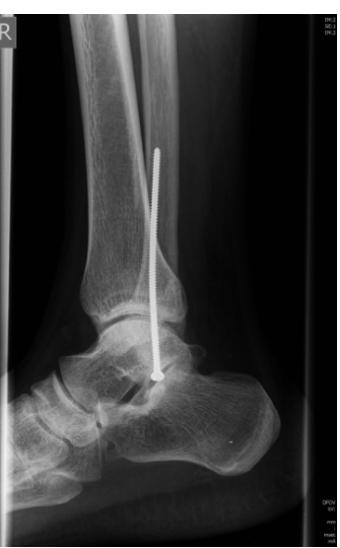

(f)
Figure 3. (a) and (b): Pre-operative X-rays; (c) and (d): Post-operative X-rays; (e) and (f): Follow up X-ray after one year showing good healing.

with one interrupted suture and gauze dressing with no cast used in these patients, and the time of non-weight bearing mobilization varies according to the fracture pattern and associated injuries. Using this percutaneous technique, the use of a tourniquet is optional. Figure 4 showing the difference in surgical approach between 
plate fixation and intramedullary screw fixation.

\section{Results}

The mechanisms of injury (Table 1) in the 46 patients included in this study were falls (43.5\%), motor vehicle accidents (34.8\%), motorcycle crashes (13\%), and direct blows (8.7\%). Evaluation of immediate postoperative roentgenograms for adequacy of reduction (Table 2) revealed a good reduction in 43 of 46 (93.5\%) patients, a fair reduction in 3 of 46 (6.5\%) patients, (Table 3). Reduction obtained in the operating room was maintained

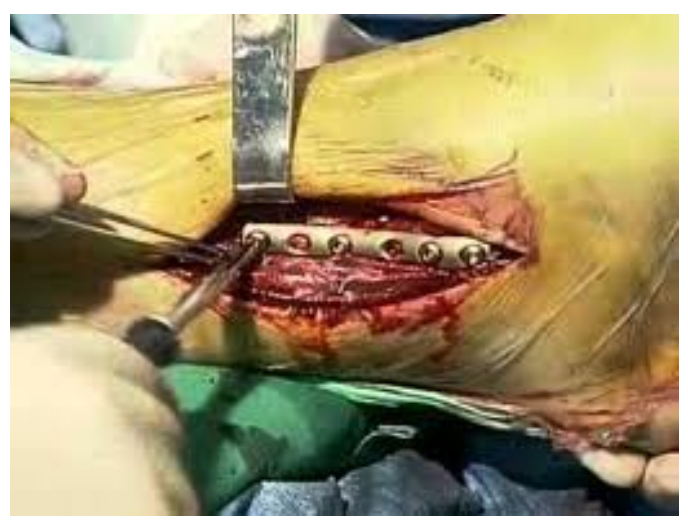

(a)

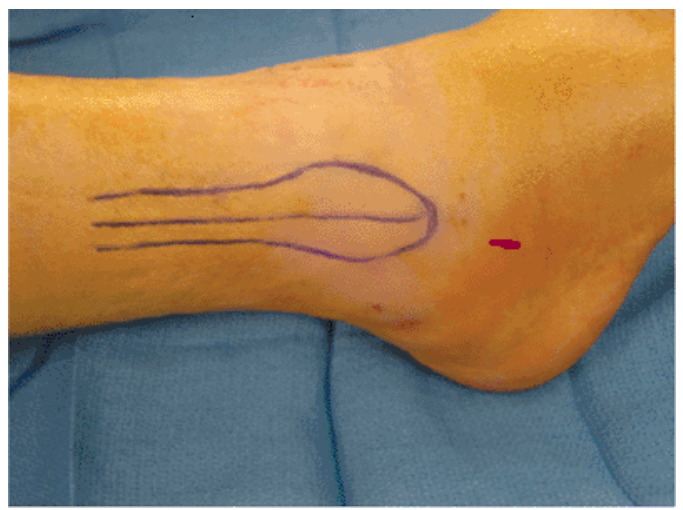

(b)

Figure 4. (a) Clinical picture showing the surgical wound needed for plate and screw fixation of lateral malleolus; (b) Clinical picture showing the surgical wound needed for Intramedullary screw fixation of lateral malleolus.

Table 1. Mechanism of injury.

\begin{tabular}{ccc}
\hline Mechanism & Number of Patients & Percentage \\
\hline Fall & 20 & 43.5 \\
Motor vehicle & 16 & 34.8 \\
Motorcycle & 6 & 13 \\
Direct blow & 4 & 8.7 \\
Total & 46 & \\
\hline
\end{tabular}

Table 2. Radiographic criteria.

\begin{tabular}{|c|c|}
\hline \multirow[t]{3}{*}{ Good } & Fibula out to length \\
\hline & $<2 \mathrm{~mm}$ of posterior displacement \\
\hline & $<1 \mathrm{~mm}$ increase in medial clear space \\
\hline \multirow[t]{3}{*}{ Fair } & Fibula shortened $<2 \mathrm{~mm}$ \\
\hline & 2 - 4 mm of posterior displacement \\
\hline & 1 - $3 \mathrm{~mm}$ increase in medial clear space \\
\hline \multirow[t]{3}{*}{ Poor } & Fibula shortened $>2 \mathrm{~mm}$ \\
\hline & $>4 \mathrm{~mm}$ of posterior displacement \\
\hline & $>3 \mathrm{~mm}$ increase in medial clear space \\
\hline
\end{tabular}

Table 3. Reduction on roentgenography.

\begin{tabular}{ccc}
\hline Rating & Number of Patients & Percentage \\
\hline Good & 43 & 93.5 \\
Fair & 3 & 6.5 \\
Poor & 0 & 0 \\
Total & 46 & \\
\hline
\end{tabular}

in all of the patients who could be followed for 6 weeks or longer (46 patients). In the 26 patients who were followed to the time of fracture union, the average time to union was 8.2 weeks.

Duration of non-weight bearing mobilization varied from 6 to 10 weeks, with an average of 8.8 weeks. Time to full weight bearing ranged from 3 to 12 weeks, with an average time to full weight bearing of 7.2 weeks. There was a $100 \%$ rate of union for all lateral malleolus fractures in this group.

No deep wound infections occurred. No patient has complained of tenderness or prominence of the hardware, and no patient has complained of impingement symptoms.

A functional rating scale (Table 4) was used to subjectively evaluate ankles in the patients who continued with clinic appointments or could be contacted by phone. Of these patients (Table 5), 25 patients (54.3\%) had an excellent result and 20 (43.5\%) were considered to have a good result. One patient $(2.2 \%)$ who had a fair functional rating had a shortened lateral malleolus (2 $\mathrm{mm})$.

Patients were evaluated for anatomic healing and not for long-term results related to degenerative arthritis.

\section{Discussions}

The importance of stable, anatomic fixation of the lateral malleolus fragment is highly appreciated to achieve satisfactory results in ankle fractures. Various methods of lateral malleolar fixation have been utilized, all with ac 
Table 4. Functional rating (compared with normal ankle).

\begin{tabular}{rr}
\hline Excellent & $\begin{array}{r}\text { Normal range of motion without pain or stiffness } \\
\text { and return to previous activity level }\end{array}$ \\
Good & $\begin{array}{r}\text { Normal range of motion without stiffness, return to previous } \\
\text { activity level with only occasional pain following activity }\end{array}$ \\
Fair & $\begin{array}{r}\text { Decreased range of motion, frequent pain following activity } \\
\text { Poor }\end{array}$ \\
\hline
\end{tabular}

Table 5. Functional results.

\begin{tabular}{ccc}
\hline Rating & Number of Patients & Percentage \\
\hline Excellent & 25 & 54.3 \\
Good & 20 & 43.5 \\
Fair & 1 & 2.2 \\
Poor & 0 & 0 \\
Total & 46 & \\
\hline
\end{tabular}

ceptable results. The most common method of fixation of lateral malleolar fractures is the buttress plating. It provides stable fixation and maintains length of the lateral malleolus.It is preferred in cases where the malleolus is comminuted, as length could not be reliably maintained with an IM screw, in compound fractures and fractures with syndesmotic injury where syndesmotic screw needed (Weber type C). The complications of plate fixation of the lateral malleolus are wound healing, especially in swollen ankles and painful, prominent hardware often develop late.

Schaffer and Manoli [10] realized that lateral hardware could lead to wound problems and they evaluated the technique described by Weber in which a buttress plate is placed posteriorly on the lateral malleolus. They described this as the "anti-glide" technique [10]. They performed biomechanical studies and demonstrated that this method of fixation was more stable than a laterally placed plate and lag screw. However, this technique is more demanding in that the surgical dissection posteriorly is difficult. Also, the hardware is left in contact with the peroneal tendons, which could cause irritation and pain.

Covino et al. [18] (in their retrospective clinical review and a biomechanical evaluation of lateral malleolus fixation) they noted no significant difference between interfragmentary versus plate fixation. They believed interfragmentary fixation avoided possible complications of lateral hardware and eliminated the possibility of screw penetration into the ankle joint. Intramedullary fixation of lateral malleolus fractures provides stable fixation without prominent subcutaneous hardware. The Intramedullary position of the hardware reduces torque and bending moment on the device. Intramedullary fixa- tion of weight bearing long bone fractures has largely replaced compression plating because of these biomechanical advantages. The advantages are also evident in the treatment of non-comminuted lateral malleolus fractures, and the technique should be utilized in indicated cases. Intramedullary fixation provides stable fixation, allowing early mobilization in this series.

Bankston, et al. [16] they found the Intramedullary screw provided $66.5 \%$ of the strength of native bone compared to the lateral buttress plate provided $61.5 \%$. This was not statistically significant, but it did prove that an Intramedullary screw provides stable fixation, thereby assuring that rehabilitation can be instituted early without the risk of loss of reduction.

If reduction of the fracture can be achieved in a closed fashion (with the aid of image intensification), we believe that fixation of a lateral malleolus fracture may be performed with an axial Intramedullary screw percutaneously. Our closed technique utilizes minimal soft-tissue dissection, thus decreasing the incidence of wound complications and painful hardware sites that are occasionally observed after open reduction and plating techniques. Other advantages include improved healing and shortened rehabilitation time because the fracture hematoma is not violated. We have initially selected only transverse or short oblique fractures as the primary candidates for this percutaneous technique. However, as our experience grows, perhaps other fracture configurations can also be treated by this method. Nevertheless, if an acceptable reduction cannot be achieved using this closed technique, one can and should proceed with open reducetion and internal fixation without hesitation and without anything lost in the process.

Our protocol may be improved upon in several areas. First of all, a prospective, randomized study comparing this percutaneous method of lateral malleolus fixation with open reduction and internal fixation with the axial screw, as well as with that of standard AO technique should be performed. The unstable lateral malleolus should be the only type of fracture included in subsequent investigations so that accurate conclusions may be drawn. To properly conduct this research, the number of patients should be increased and a longer follow-up period would be mandatory. Finally, use of more rigid subjective and objective criteria would allow more specific conclusions to be drawn about the patients' long-term functional results.

\section{Conclusion}

Intramedullary screw fixation of lateral malleolus requires minimal soft-tissue dissection, thereby decreasing wound complications and painful hardware sites that are occasionally observed after open techniques. This closed 
technique also eliminates screw penetration of the ankle joint and damage to the peroneal tendons, which can be risks when a plate or lag screws are employed as internal fixation. Surgical time is also reduced and tourniquet use is optional. If an acceptable reduction cannot be obtained using this technique, open reduction and internal fixation should be performed.

\section{REFERENCES}

[1] H. Bolin, "The Fibula and Its Relationship the Tibia and Talus in Injuries of the Ankle Due to Forced External Rotation,” Acta Radiologica, Vol. 56, No. 6, 1961, pp. 439-448. doi:10.3109/00016926109172839

[2] M. C. Harper, "An Anatomic Study of the Short Oblique Fracture of the Distal Fibula and Ankle Stability," Foot Ankle, Vol. 4, No. 1, 1983, pp. 23-29. doi:10.1177/107110078300400106

[3] M. Bauer, et al., "Malleolar Fractures: Nonoperative versus Operative Treatment. A Controlled Study,” Clinical Orthopaedics and Related Research, Vol. 199, 1985, pp. 17-27.

[4] K. E. Bugler, C. D. Watson, A. R. Hardie, P. Appleton, M. M. Mcqueen, C. M. Court-Brown and T. O. White, "The Treatment of Unstable Fractures of the Ankle Using the Acumed Fibular Nail," The Journal of Bone \& Joint Surgery, Vol. 94-B, No. 8, 2012, pp. 1107-1112. doi:10.1302/0301-620x.94b8.28620

[5] H. N. Burwell and A. D. Charnley, "The Treatment of Displaced Fractures at the Ankle by Rigid Internal Fixation and Early Joint Movement," The Bone \& Joint Journal, Vol. 47, No. 4, 1965, pp. 634-660.

[6] L. J. de Souza, R. B. Gustilo and T. J. Meyer, "Results of Operative Treatment of Displaced External RotationAbduction Fractures of the Ankle," The Journal of Bone \& Joint Surgery, Vol. 67, No. 7, 1985, pp. 1066-1074.

[7] W. C. McDade, “Treatment of Ankle Fractures," AAOS Instructional Course Lectures, Vol. 24, 1975, pp. 251-294.

[8] N. F. SooHoo, L. Krenek, M. J. Eagan, B. Gurbani, C. Y. Ko and D. S. Zingmond, "Complication Rates Following Open Reduction and Internal Fixation of Ankle Fractures," The Journal of Bone \& Joint Surgery, Vol. 91,
2009, pp. 1042-1049.

[9] F. C. Wilson and L. A. Skilbred, "Long-Term Results in the Treatment of Displaced Bimalleolar Fractures," The Journal of Bone \& Joint Surgery, Vol. 48, No. 6, 1966, pp. 1065-1078.

[10] J. J. Schaffer and A. Manoli, “The Antiglide Plate for Distal Fibular Fixation. A Biomechanical Comparison with Fixation with a Lateral Plate," The Journal of Bone \& Joint Surgery, Vol. 69, No. 4, 1987, pp. 596-604.

[11] K. A. Solonen and L. Lauttamus, "Operative Treatment of Ankle Fractures,” Acta Orthopaedica Scandinavica, Vol. 39, No. 2, 1968, pp. 223-237.

[12] C. Olerud and H. Molander, "Bi- and Trimalleolar Ankle Fractures Operated with Nonrigid Internal Fixation," Clinical Orthopaedics and Related Research, Vol. 206, 1986, pp. 253-260.

[13] J. L. Hughes, et al., "Evaluation of Ankle Fractures: Non-Operative and Operative Treatment," Clinical Orthopaedics and Related Research, Vol. 138, 1979, pp. 111-119.

[14] F. Jergesen, "Open Reduction of Fractures and Dislocations of the Ankle," The American Journal of Surgery, Vol. 98, No. 2, 1959, pp. 136-151. doi:10.1016/0002-9610(59)90057-1

[15] C. L. Mitchell and J. L. Fleming, "Fractures and Fracture-Dislocations of the Ankle," Postgraduate Medicine, Vol. 26, 1959, pp. 773-782.

[16] A. B. Bankston, L. D. Anderson and P. Nimityongskul, "Intramedullary Screw Fixation of Lateral Malleolus Fractures,” Foot \& Ankle International, Vol. 15, No. 11, 1994, pp. 599-607. doi:10.1177/107110079401501105

[17] T. D. Ray, P. Nimityongskul and L. D. Anderson, "Percutaneous Intramedullary Fixation of Lateral Malleolus Fractures: Technique and Report of Early Results," Journal of Trauma, Vol. 36, No. 5, 1994, pp. 669-675. doi:10.1097/00005373-199405000-00012

[18] B. M. Covino, C. M. Barsanti, J. Wolfe and G. J. Wang, "Internal Fixation of Lateral Malleolus Fractures: A Clinical and Biomechanical Comparison of Two Techniques,” Orthopaedics Transaction Journal, Vol. 5, 1990, p. 90. 